a succession of films (drained by cellulose threads to blackness) in a McBain apparatus. Even more valuable would be a trial of the forces at the black boundary by the Langmuir-Adams method, using quite a small trough or film-frame in a moteless Dewar enclosure.

After years of observation I find it difficult therefore to aecept that one oriented layer and one irregular reserve layer below this on either face, and nothing but chaos between, can explain the appearances presented by soap films, or maintain their tenacity under such conditions as have been described.

Royal Institution,

Albemarle Street, W.1, June 25.

W. J. Green.

\section{Daily Variations of Temperature.}

In the discussion on the "Irregular Variations of Temperature in London " (NATURE, 126, 61) the case of periods of several days was in question, and smoothed averages were taken. Some years ago I was



FIG. 1.-Daily temperatures, average of 50 years. Full wavy line, Greenwich; full smooth line, the nearest sine curves for Greenwich maxima. Vertical lines are numbered with day of year,
and these are placed where a minimum occurs in all the records.

must be due to some cause of deficiency. It will be seen that at the vertical lines (marked with the daynumber in the year) each of the records shows a minimum; such a deficiency cannot therefore be due to a local cause. The only obvious cause would be the interposition of streams of minute asteroids in regular orbits. To study this farther would need the comparison of records from a large number of positions, over short terms of years, as orbits may shift by precession. The zodiacal light seems only explicable as due to a large diffusion of matter between the earth and sun, certainly extending as far as the earth's orbit. Fuinders Petrie.

Sir Flinders Petrie's suggestion that regular periods of low temperature may be caused through partial cutting off of the sun's rays by cosmic dust is an old one, but is not supported by any real evidence. In Britain temperature is governed far more by wind direction and cloud amount than by solar radiation, especially in winter, when it is practically independent of latitude. The only real test of the cosmical hypothesis would be the examination of averages over a number of years of the daily measurements of solar radiation made by the Smithsonian Astrophysical Observatory. I do not think this test has yet been made; probably the number of observations is still insufficient. The occasional agree. ments between minima at different stations, shown on Sir Flinders Petrie's curves, may be due to the frequent occurrence of extensive systems of northerly winds on those days, or may be merely accidental coincidences. C. E. P. Brooks.

\title{
Bird Flotation.
}

Is commenting on a paper of mine in NaTURE of June 14, p. 902, it is suggested that the ability of a bird to extend its feathers further from the skin may enable it to displace a greater volume of water when afloat than the volume measurable to the same surface level when ashore.

Undoubtedly this ability does exist, but, in comment upon the suggestion, I would like to point out that, if the displaced volume were materially increased in this manner

attracted by the daily irregularities observed at Greenwich, in averages of fifty years, and compared them with those of other available records, Falmouth, Kew, Valentia, and Aberdeen. I wished to have in cluded Buitenzorg, but the volume of records was missing from the Royal Society library.

The results are in the diagram (Fig. 1). The maxima will represent the true solar effect, as we do not know of any other cause of heat; all below the maxima the bird could not maintain an upright position but would overturn. This instability is due to the lowering of the metacentre, so that it would be brought well below the centre of gravity of the bird. The facts can be ascertained by calculation and experiment. A duck was provided with a waterproof jacket fitting closely against the underbody feathers; when put afloat, the freeboard of this bird was about one-eighth of an inch less than without the

No. 3173, VoL. 126] 